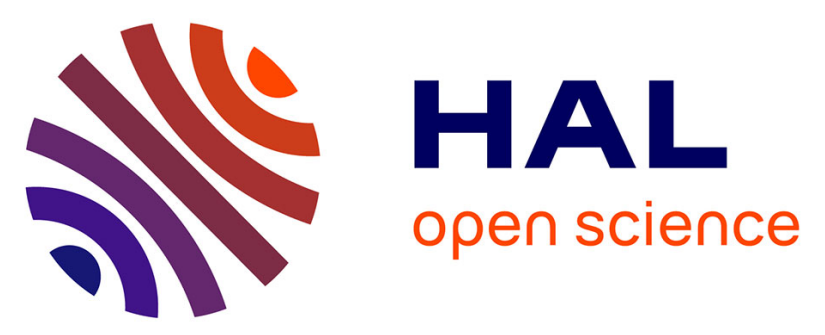

\title{
The impact of Mount Etna sulfur emissions on the atmospheric composition and aerosol properties in the central Mediterranean: a statistical analysis over the period 2000-2013 based on observations and Lagrangian modelling
}

Pasquale Sellitto, Claudia Zanetel, Alcide Di Sarra, Giuseppe Salerno, Andrea

Tapparo, Daniela Meloni, Giandomenico Pace, Tommaso Caltabiano, Pierre Briole, Bernard Legras

\section{To cite this version:}

Pasquale Sellitto, Claudia Zanetel, Alcide Di Sarra, Giuseppe Salerno, Andrea Tapparo, et al.. The impact of Mount Etna sulfur emissions on the atmospheric composition and aerosol properties in the central Mediterranean: a statistical analysis over the period 2000-2013 based on observations and Lagrangian modelling. Atmospheric Environment, 2017, 148, pp.77-88.

10.1016/j.atmosenv.2016.10.032 . hal-01386811

\section{HAL Id: hal-01386811 \\ https://hal.sorbonne-universite.fr/hal-01386811}

Submitted on 24 Oct 2016

HAL is a multi-disciplinary open access archive for the deposit and dissemination of scientific research documents, whether they are published or not. The documents may come from teaching and research institutions in France or abroad, or from public or private research centers.
L'archive ouverte pluridisciplinaire HAL, est destinée au dépôt et à la diffusion de documents scientifiques de niveau recherche, publiés ou non, émanant des établissements d'enseignement et de recherche français ou étrangers, des laboratoires publics ou privés. 


\title{
The impact of Mount Etna sulfur emissions on the atmospheric composition and aerosol properties in the central Mediterranean: a statistical analysis over the period 2000-2013 based on observations and Lagrangian modelling
}

\author{
Pasquale Sellitto $^{\mathrm{a}, *}$, Claudia Zanetel ${ }^{\mathrm{b}}$, Alcide di Sarra ${ }^{\mathrm{c}}$, Giuseppe Salerno ${ }^{\mathrm{d}}$, \\ Andrea Tapparo $^{\mathrm{b}}$, Daniela Meloni ${ }^{\mathrm{c}}$, Giandomenico Pace ${ }^{\mathrm{c}}$, Tommaso \\ Caltabiano $^{\mathrm{d}}$, Pierre Briole ${ }^{\mathrm{e}}$, Bernard Legras ${ }^{\mathrm{a}}$ \\ ${ }^{a}$ Laboratoire de Météorologie Dynamique, UMR8539, CNRS - École Normale \\ Supérieure/Université Pierre et Marie Curie/Ecole Polytechnique, Paris, France \\ ${ }^{b}$ Dipartimento di Scienze Chimiche, Universitá di Padova, Padova, Italy \\ ${ }^{c}$ ENEA, Laboratory for Observations and Analyses of Earth and Climate \\ (SSPT-PROTER-OAC), Rome, Italy \\ ${ }^{d}$ Istituto Nazionale di Geofisica e Vulcanologia, Catania, Italy \\ ${ }^{e}$ Laboratoire de Géologie, UMR8538, CNRS - École Normale Supérieure, Paris, France.
}

\begin{abstract}
The emission of gases and aerosols due to volcanic activity may impact significantly atmospheric composition, cloud occurrence and properties, and the regional and global climate. While the effects of strong explosive (stratospheric) eruptions are relatively well known, limited information on the impacts of small to moderate volcanic activities, including passive degassing, is available. In this paper, the downwind impact of Mount Etna's sulfur emissions on the central Mediterranean is investigated on a statistical basis over the period 2000-2013 using: (a) daily sulfur dioxide emission rates measured near crater at Mount Etna with ground-based ultraviolet spectrophotometers, (b) Lagrangian trajectories and simulated plume dispersion obtained with the FLEXPART (FLEXible PARTicle dispersion) model, and (c) long-term observations of column $\mathrm{SO}_{2}$ concentration and aerosol Ångström exponent $\alpha$ at Lampedusa $\left(35.5^{\circ} \mathrm{N}, 12.6^{\circ} \mathrm{E}\right)$.
\end{abstract}

\footnotetext{
*Corresponding author, Phone number: 0033 (0)6 83350957.

Email address: psellitto@lmd.ens.fr (Pasquale Sellitto)
} 
This statistical analysis has allowed, for the first time, the characterization of decadal impact of Mount Etna's sulfur emissions on the sulfur dioxide and the aerosol microphysical/optical properties in the central Mediterranean. On average, statistically significant higher $\mathrm{SO}_{2}$ concentrations and smaller aerosol sizes are present when air masses from Mount Etna overpass Lampedusa. Despite being upwind of Lampedusa for only $5 \%$ of the time, Mount Etna is potentially responsible for up to $40 \%$ and $20 \%$ of the $\mathrm{SO}_{2}$ and $\alpha$ extreme values (exceedances of a fixed threshold), respectively, at this location. The most important factor determining this perturbation is the prevailing dynamics, while the magnitude of the $\mathrm{SO}_{2}$ emission rates from Mount Etna appears to be likely important only for relatively strong emissions. The observed perturbations to the aerosol size distribution are expected to produce a direct regional radiative effect in this area.

Keywords: Volcanic emissions, sulfur cycle, secondary sulfate aerosols, regional climate, Mediterranean, Mount Etna

\section{Introduction}

The gaseous and particulate matter emissions due to volcanic activity may produce an important impact on the tropospheric and stratospheric composition [1, the distribution and optical properties of low [e.g., 2] and high clouds [e.g., 3], the Earth radiation budget from the regional to the global scale, and climate [4. The effect on the stratospheric composition and the global radiative balance of strong explosive eruptions (strong enough for the effluents to reach the stratosphere) is dominated by the highly reflective sulfate aerosols formed by the gas-to-particle conversion, involving volcanic sulfur dioxide $\left(\mathrm{SO}_{2}\right)$ emissions [5]. Due to the long lifetime of sulfate aerosols in the stratosphere (up to a few years for very strong eruptions) and the stratospheric dynamics (dominated by the poleward Brewer-Dobson circulation), the cooling effect produced by these secondary sulfate aerosols can act at the global scale [6]. The stratospheric aerosol perturbation and the direct radiative forcing of strong explosive 
eruptions is relatively well known, and has been observed for several recent eruptions, see, e.g. the cases of Mount Pinatubo (1991) [e.g., 7], Kasatochi (2008) [e.g., 8, Sarychev (2009) [e.g., 9] and Nabro (2011) volcanoes [e.g., 10]. On the contrary, the influence of the more frequent weak volcanic activity, including passive degassing, on the tropospheric aerosol properties and on the regional radiation budget is still largely unknown. As for stratospheric eruptions, most of the radiative effects of moderate eruptions are associated with changes of the aerosol size distribution, composition, and shape. Emission of primary particles, mainly ash, and secondary aerosols through gas-to-particle conversion of volatile sulfur compounds affect the aerosol properties.

Mount Etna is one of the most important emitters of gases and particles on Earth, accounting for about $10 \%$ of the global average volcanic emissions of carbon dioxide and $\mathrm{SO}_{2}$ [1]. Its continuous degassing and episodic explosive eruptions are important sources of particles and gases for the Mediterranean atmosphere. The total mass of gaseous sulfur compounds emitted by Mount Etna 30 is estimated to be $0.7 \times 10^{6}$ tonnes of sulfur per year, which corresponds to about ten times the anthropogenic emissions in the same area [12. Please note that the emissions estimations by Graf et al. 12 are based on data which date back to the end of the 1980s. Since then, the anthropogenic $\mathrm{SO}_{2}$ emissions in Europe have been drastically reduced (up to about $75 \%$ from the year 1990 to the 35 year 2010, see, i.e. http://www.eea.europa.eu/data-and-maps/indicators/eea32-sulphur-dioxide-so2-emissions-1/assessment-3). Thus, the volcanic source of sulfur compounds has become more and more important, relatively to the anthropogenic source, during the last few decades. In addition, volcanic sulfur emissions are more efficient climate forcers than anthropogenic (pollution) emissions because they are released at higher altitudes, and the produced sulfate aerosols have longer lifetimes [13]. The impact of Mount Etna on the atmospheric composition, the aerosol chemical, microphysical, and optical properties, the cloud occurrence and properties, the radiative balance and the regional climate in the Mediterranean are not sufficiently known and probably underestimated. Recently, using an individual case study, it has been shown that Mount 
Etna emissions may produce a detectable effect on the aerosol microphysical and optical properties in the central Mediterranean, during periods when this region is exposed to volcanic air masses originating from Mount Etna [14. This perturbation to the local and regional aerosol layer has the potential to produce non-negligible radiative perturbations. Using radiative transfer simulations, the radiative forcing efficiency (radiative forcing per unit aerosol optical depth) of modelled Etnean volcanic plumes has been found comparable with the efficiency of the frequent Saharan dust or pollution transport events in the Mediterranea area [15]. This analysis was based on a single case study, and a more extended, long-term characterisation of this impact is still lacking.

In this paper, the downwind impact of Mount Etna's $\mathrm{SO}_{2}$ emissions in the central Mediterranean is estimated over the period 2000-2013 using the longterm observations of $\mathrm{SO}_{2}$ column and aerosol Ångström exponent $\alpha$ at the ENEA (Italian National Agency for New Technologies, Energy, and Sustainable Economic Development) Station for Climate Observations on the small island of Lampedusa $\left(35.5^{\circ} \mathrm{N}, 12.6^{\circ} \mathrm{E}\right)$.

It must be pointed out that in the Mediterranean $\mathrm{SO}_{2}$ may originate from different sources, both natural and anthropogenic (e.g., in addition to the volcanic source, combustion, ships, biogenic and marine sources [e.g., 16, 17]). 65 Similarly, fine particles are associated with polluted air masses and secondary aerosols, with biomass burning particles [e.g., 18, 19], and with new particle nucleation cases, e.g. [e.g., 20]. Moreover, observed column optical properties may be the result of the overlapping of different types of particles at different altitudes. Thus, the determination of the volcanic source based only on values of $\mathrm{SO}_{2}$ column and aerosol Ångström exponent is intrinsically equivocal, and a more complex approach is necessary. Therefore, the determination of a possible Etna influence on the $\mathrm{SO}_{2}$ column and aerosol column optical properties must be made on a long-term statistical basis, combining available information on the source and on the transport processes.

The observations at Lampedusa are thus linked to the information on the volcanic source, in terms of 1) the dynamical processes, using a long series of 
trajectories and plume dispersion calculations obtained with Lagrangian modelling, and 2) Mount Etna $\mathrm{SO}_{2}$ emissions derived from the long-term series of daily $\mathrm{SO}_{2}$ emission rates near-source measurements. This statistical analysis allows, for the first time, the characterization of the impact of Mount Etna's sulfur emissions to the $\mathrm{SO}_{2}$ concentrations and the aerosol microphysical/optical properties in the central Mediterranean, and then possibly on the radiative budget.

The paper is structured as follows. Data and methods used in this work are introduced in Sect. 22 the results of our analysis are given in Sect. 3, conclusions are drawn in Sect. 4 .

\section{Data and methods}

\subsection{Near source and downwind observations}

\subsubsection{Sulfur dioxide emission rate measurements at Mount Etna}

Measurements of bulk $\mathrm{SO}_{2}$ emission rates from the volcanic plume of Mount Etna have been conducted routinely between years 2000 and 2014 using remote ground-based ultraviolet (UV) spectroscopy techniques. Three different spectrometers and methods have been employed throughout the 15-year period: discrete sampling by COrrelation SPECtrometer (COSPEC) 21, 22, CCD (charge-coupled device)-based ultraviolet-visible devices [e.g. 23, 24], and automatic observation using an array of permanent ultraviolet scanning spectrometers (FLAME - FLux Automatic Measurement) 25]. The different instruments were replaced gradually over the course of years, after comparing and validating the results obtained by the three techniques [26].

$\mathrm{SO}_{2}$ measurements have been carried out with COSPEC and CCD-based spectrometers (USB2000 Ocean Optics) from 2000 to 2004; these measurements were made three times per week, and with increased frequency during eruptive activity. As in the more common COSPEC method, UV radiation spectra were collected using a zenith-viewing telescope traversing beneath the volcanic plume of Mount Etna from a distance of 7-15 km from the summit craters to 
produce $\mathrm{SO}_{2}$ cross-sections. The roads followed during the $\mathrm{SO}_{2}$ measurement sessions were selected according to the prevailing wind direction at the time of measurement. The geographic position during traverses was acquired with a GPS (Global Positioning System) receiver. $\mathrm{SO}_{2}$ column amounts along the traverses were retrieved in real-time by combining information from the retrieved spectra and position. In a day of measurements, data from 4-6 traverses were generally averaged and used to compute daily emission rates by multiplying the integrated $\mathrm{SO}_{2}$ cross-section by wind velocity - provided by the Italian Air force Meteorological service. The uncertainty associated with the $\mathrm{SO}_{2}$ flux typically ranges from \pm 13 to $\pm 20 \%$, mainly due to the uncertainty in wind-plume speed estimation [21, 27.

Between late 2004 and 2014, $\mathrm{SO}_{2}$ flux measurements were robotically carried out using the FLAME network. The network consists of ten ultraviolet scanning spectrometers, spaced about $7 \mathrm{~km}$ apart and placed at an altitude of about 500 $\mathrm{m}$ above sea level, on the flanks of Mount Etna. Each device of the network scans the sky in a vertical plane over about $156^{\circ}$, almost horizon-to-horizon, for almost 9 hours daily, intersecting the plume at a mean distance of about $14 \mathrm{~km}$ from the summit craters and acquiring a complete scan in about 5 min. At each scan, UV radiation in the 295-375 $\mathrm{nm}$ spectral range, where $\mathrm{SO}_{2}$ absoprtion bands are located, is measured with a spectral resolution of 0.6-0.9 $\mathrm{nm}$ (full width half height). Open path ultraviolet spectra are reduced on site applying the DOAS (Differential Optical Absorption Spectrometry) technique 28] using a modelled clear-sky spectrum [25. $\mathrm{SO}_{2}$ Slant Column Amounts (SCA) are then retrieved. The concurrent ozone absorption and the Ring effect are taken into account in the DOAS calculations. From the observed spectra, the $\mathrm{SO}_{2}$ mass flux can be derived using the method described by Stoiber et al. 21. First, the $\mathrm{SO}_{2} \mathrm{SCA}$ in the perpendicular plane of the scan (e.g., in $\mathrm{kg} \mathrm{m}^{-1}$ ) is obtained by integrating each SCA of the scan. Then, it is multiplied by the estimated plumetransport speed (i.e. the wind speed) to determine the emission rate. Finally, individual emission rates are summed over the whole plume to obtain the total emissions for a given scan. Uncertainty in computed flux ranges between -22 
and $+36 \%$ [26]. The complete inversion algorithm is thouroghly described in [25.

In the present work, a time series of daily $\mathrm{SO}_{2}$ emission rates, covering the time interval 2000-2013, is used (see Fig 1a), by combining the observations from the two aforementioned techniques. Some gaps in the time series have occurred, due to instrumental malfunctioning or adverse weather conditions.

\subsubsection{Sulfur dioxide column anomaly measurements at Lampedusa}

The $\mathrm{SO}_{2}$ total column amount (i.e., the concentration on a vertical column extending from the surface to the top of the atmosphere) is routinely monitored at Lampedusa. The $\mathrm{SO}_{2}$ column amount is measured with a MK III Brewer UV spectrophotometer 29], which is part of a large set of instruments operating at this station. The MK III Brewer spectrophotometer is a doublemonochromator ground-based remote sensor developed to measure total ozone, $\mathrm{SO}_{2}$ [30], and spectral ultraviolet irradiance [e.g., 31]. More recently, the measurement capability of the Brewer has been extended to the determination of the AOD (Aerosol Optical Depth) [32, 33]. The basic total ozone and $\mathrm{SO}_{2}$ observations are performed by pointing at the Sun (direct Sun, DS, observations) and taking measurements at five wavelengths $(306.3,310.1,313.5,316.8$, and $320.1 \mathrm{~nm}$ ), used to derive total ozone and $\mathrm{SO}_{2}$ with a DOAS algorithm. Total ozone and $\mathrm{SO}_{2}$ are measured in Dobson units (DU). Each direct sun ozone and $\mathrm{SO}_{2}$ determination is obtained from five successive measurements; for typical measurements with the double monochromator Brewer in Lampedusa in fine weather conditions the standard deviation of the five successive ozone measurements is within $1 \%$, and the that of the five $\mathrm{SO}_{2}$ measurements is about $0.2-0.5$ DU.

In the present work, daily $\mathrm{SO}_{2}$ data covering the time interval 2000-2013 are used (see Fig. 1b). Some gaps in the time series have occurred, due to instrumental malfunctioning or adverse weather conditions.

165 In order to identify cases with a possible influence of the volcanic plume on the $\mathrm{SO}_{2}$ measured at Lampedusa we have to look for short-term (of the order of 
a maximum of few days, due to the chemical losses and changes of the emission conditions and dynamical patterns from Etna to Lampedusa) enhancements of the column $\mathrm{SO}_{2}$. Thus, we have first de-seasonalised the column $\mathrm{SO}_{2}$ data. This was made by computing monthly average values from the data below $3.3 \mathrm{DU}$, and by subtracting the monthly average from the daily values in each month. Thus, we obtain a long-term series of daily column $\mathrm{SO}_{2}$ anomalies. Due to the small number of values exceeding 3.3 DU, the anomaly values are distributed around zero. We have used the $\mathrm{SO}_{2}$ anomalies in the following analysis.

\subsubsection{Angström exponent measurements at Lampedusa}

Aerosol optical properties are routinely monitored by a Cimel Sun-photometer and a Multi-Filter Rotating Shadowband Radiometer (MFRSR) at Lampedusa. These instruments measure the AOD at different wavelengths. The AOD at a fixed wavelength is linked to the monochromatic attenuation by aerosols of a radiation beam propagating vertically, and measures the extinction of radiation due to aerosols. The CE-318 Cimel sun photometer \#172 installed at the ENEA laboratory is part of the Aerosol Robotic Network (AERONET, http://aeronet.gsfc.nasa.gov/). The photometer is programmed to perform either DS or sky radiance measurements several times a day, and the AOD is typically obtained every $15 \mathrm{~min}$. Operational wavelengths of the Cimel are 340, $380,440,500,675,870,940$, and $1020 \mathrm{~nm}$. The MFRSR is a radiometer that collects sky radiation through a horizontal diffuser, and uses a rotating shadow band to separately measure the global and diffuse components of the radiative field. The direct component is derived as the difference between the two measurements. The visible MFRSR, model MFR-7, has a channel for the total shortwave radiation, and six channels centred respectively at 416, 496, 615, 673, 869, and $940 \mathrm{~nm}$. More details on the Cimel and MFRSR measurements at Lampedusa are given by di Sarra et al. [34]. They developed an integrated Cimel-MFRSR dataset which includes a correction for forward scattering by large particles, which leads to an underestimate of the AOD for moderate and large values of the aerosol loading. This dataset is used in this study. The esti- 
mated uncertainty on the retrieved AOD is between 0.01 and 0.2. The Ångström law describes the AOD dependency on wavelength:

$$
\operatorname{AOD}(\lambda)=\beta \lambda^{-\alpha}
$$

In Eq. 1. $\lambda$ is expressed in $\mu \mathrm{m}$ and $\beta$ is the modelled AOD at $1.0 \mu \mathrm{m}$. Equation 1 is used to calculate the Ångström exponent $\alpha$ :

$$
\alpha=-\frac{\ln \left(\operatorname{AOD}\left(\lambda_{1}\right) / \operatorname{AOD}\left(\lambda_{2}\right)\right)}{\ln \left(\lambda_{1} / \lambda_{2}\right)},
$$

where $\lambda_{1}$ is $500 \mathrm{~nm}$ and $\lambda_{2}$ is $870 \mathrm{~nm}$. Large values of $\alpha$ are associated with small particles and vice-versa [35]. The uncertainty on the Ångström exponent depends on the AOD, and may be large for low values of the optical depth. The uncertainty on $\alpha$ is typically of the order of 0.5 for an AOD at $500 \mathrm{~nm}$ of 0.19 (long-term annual mean AOD at Lampedusa [34]), and an Ångström exponent of 1. Larger uncertainties are associated with smaller values of the AOD.

The time series of daily column-average values of $\alpha$, covering the time interval 2000-2013, is used in this work (see Fig. 11).

\subsubsection{Definition of exceedance thresholds for $\mathrm{SO}_{2}$ emission rates, and downwind} $\mathrm{SO}_{2}$ anomalies and Angström exponents

Our analyses are based on both absolute values of the near source and downwind parameters, and the occurrence of extreme values, i.e., values that exceed fixed thresholds, thus indicating an anomalously high value. In the following, these occurrences are concisely referred to as exceedances, i.e. exceedances of the threshold.

A threshold value of $40 \mathrm{~kg} \mathrm{~s}^{-1}$ was chosen to select exceedances for the near source $\mathrm{SO}_{2}$ emission rate. We have fixed this threshold to isolate stronger eruptive events, or degassing activity with consistent $\mathrm{SO}_{2}$ emissions, from the continuous passive degassing activity. Please note that this threshold is somehow arbitrary, and chosen based on the visual inspection of the time series, compared to the literature information about Mount Etna activity. 

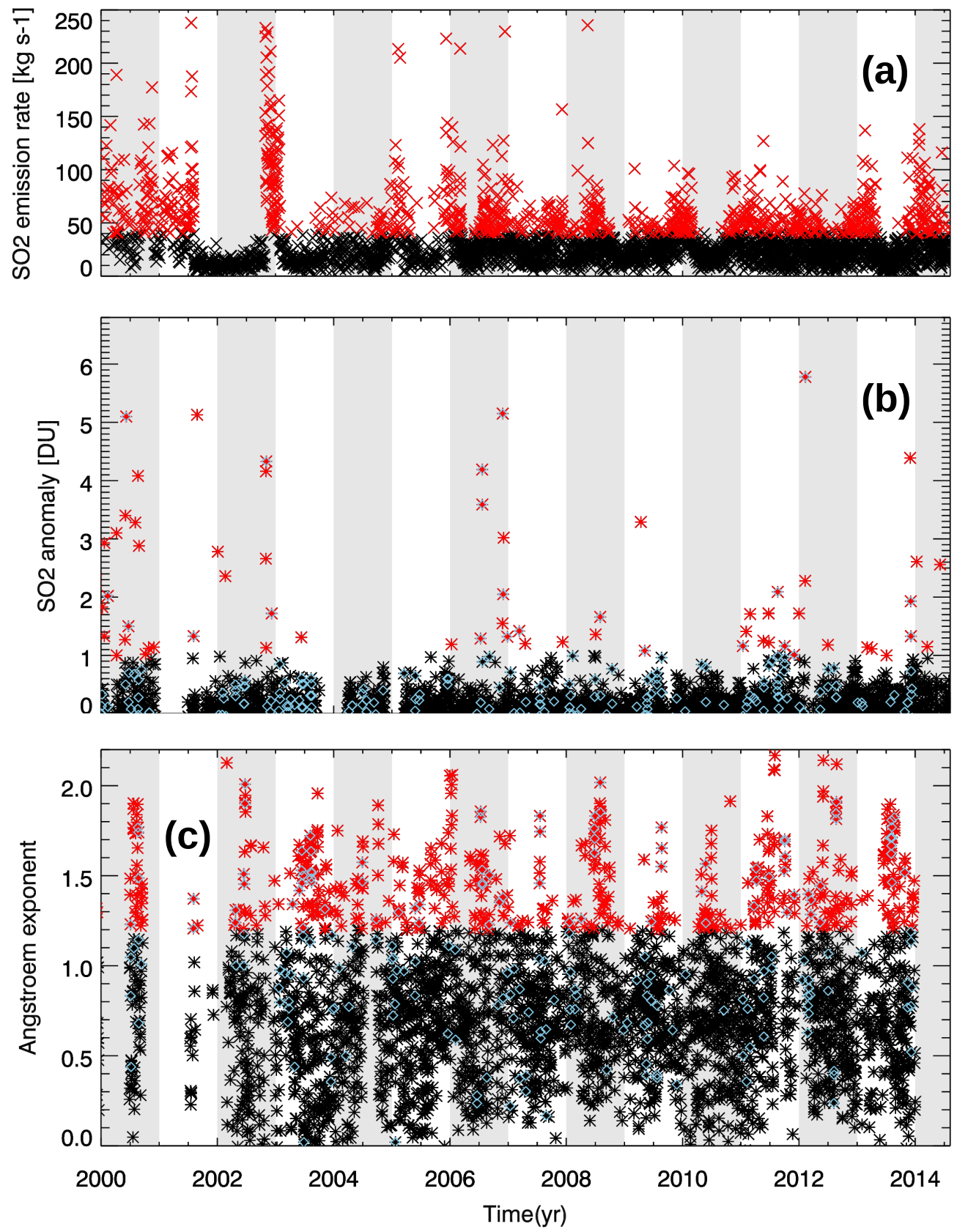

Figure 1: (a) Near source $\mathrm{SO}_{2}$ emission rates at Mount Etna, from COSPEC, CCD and the FLAME network; (b) $\mathrm{SO}_{2}$ total column anomalies, from Brewer observations and (c) Ångström exponent, from Cimel/MFRSR combined observations at Lampedusa. For the three parameters, the time-series spanning from 2000 to 2013 is shown (as used in the analyses of the present paper). Even years (2000, 2002, etfo and odd years (2001,2003, etc) alternate grey and white backgrounds, respectively. Data points with values exceeding selected thresholds, $40 \mathrm{~kg} \mathrm{~s}^{-1}$ for the $\mathrm{SO}_{2}$ emission rates, 1.0 DU for the $\mathrm{SO}_{2}$ anomaly and 1.2 for the Ångström exponent are shown in red. Sulfur dioxide anomaly and $\alpha$ data points for class 1 trajectories, as defined in Sect. 3.2 are identified as sky blue diamonds. 
A threshold value of 1.0 DU is chosen for the downwind $\mathrm{SO}_{2}$ column anomaly at Lampedusa. This value is considered as a significant deviation from background values, and may be associated with the overpass of $\mathrm{SO}_{2}$-rich volcanic plumes.

A threshold value of 1.2 is chosen for the downwind Ångström exponent at Lampedusa. As done by Sellitto et al. [14, this value is selected as to isolate relatively small sized particles. Throughout this work, Mount Etna's plume as observed at Lampedusa is assumed to be an aged volcanic plume, rich in sub-micrometric sulphate droplets due to the gas-to-particle conversion of $\mathrm{SO}_{2}$ emissions. Lampedusa is about $350 \mathrm{~km}$ South-West of Mount Etna. According to our trajectory analyses, the air masses travelling over Mount Etna reach Lampedusa within about 1 to 2 days. The $\mathrm{SO}_{2}$ lifetime at the typical injection altitudes has been estimated as varying between a few hours and a few days for this volcano (injection altitudes from about 3.5 up to $10-12 \mathrm{~km}$ above sea level) [14, 36]. In case of volcanic plume detection at Lampedusa, the coarse ash component is supposed to be significantly reduced by gravitational settling (see simulations in [14]), leaving mostly small sulphate and/or fine ash particles. Following this discussion, we identify a volcanic signature by anomalously small particles and, correspondingly, relatively large values of the Ångström exponent. It is worth noticing that previous Ångström exponent observations for Mount Etna's plume [37, 38], as well as for other volcanoes, see, i.e., [39], have shown values higher than 1.0. Previous studies have shown that the aerosol optical characterisation at Lampedusa, including the Ångström exponent, can vary relatively fast, depending on air mass origin [19]. While, extreme values of the Ångström exponent are found for aerosol types like desert dust (0.15 average $\alpha$, over the period July 2001-September 2003) or urban/biomass burning particles (1.77 average $\alpha$, over the same period), the properties of volcanic aerosols from Mount Etna have still not been isolated at Lampedusa. 


\subsection{Plume dispersion and air masses trajectories simulations with FLEXPART}

The FLEXible PARTicle dispersion (FLEXPART) model is a tool for atmospheric Lagrangian transport and dispersion modeling and analysis [40. FLEXPART computes trajectories of a large number of air parcels to describe the transport and diffusion of tracers in the atmosphere. FLEXPART can calculate both forward and backward trajectories and dispersion; it is an off-line model that uses meteorological fields from different sources, including the European Centre for Medium range Weather Forecast (ECMWF) analyses, on a latitude/longitude grid. In its forward simulations, it models the mesoscale and long-range transport, diffusion, and plume trajectories of tracers released from a source. It takes into account removal processes as dry and wet deposition. The atmospheric transport is the same for all chemical species, but individual particles can represent several chemical species, each type differently affected by the removal processes.

The dispersion of $\mathrm{SO}_{2}$ from Etna is simulated in this work. We first performed forward modelling calculations to simulate the dispersion of $\mathrm{SO}_{2}$ from the Mount Etna $\left(14.99^{\circ} \mathrm{E}, 37.75^{\circ} \mathrm{N}\right)$ source and to describe the $\mathrm{SO}_{2}$ and aerosol downwind propagation at the regional scale. The $\mathrm{SO}_{2}$ simulations are initialized with the daily emission rates observed by COSPEC-CCD-FLAME using the method described in Sect. 2.1.1. Although Mount Etna has a multiple active crater structure, it has been modelled as a single volcanic source. In fact, the distance between the active summit craters (a few hundreds meters) is negligible with respect to the considered transport scales (a few hundreds kilometers). Due to the lack of a systematic information on the injection altitude for both explosive and degassing activity, the altitude of the emissions has been chosen to be at: a) a fixed altitude of $3500 \mathrm{~m}$ (Etna's summit) for the general case, and b) the interval 3500 to $7000 \mathrm{~m}$ for emissions exceeding a fixed threshold (40 $\mathrm{kg} \mathrm{s}^{-1}$ ), to account for possible paroxysmal activity linked to stronger emissions. This assumption leads to uncertainties on the downwind distribution due to the variability of the winds field and the dispersion as a function of altitude. Methodologies are under investigation to estimate the 
injection altitude from other archived volcanologic parameters, from satellite observations or from the emission rates themselves. The total target area for this study is $10.00-17.00^{\circ} \mathrm{E} / 33.00-40.00^{\circ} \mathrm{N}$ with a resolution of $1^{\circ} \mathrm{x} 1^{\circ}$. The simulations extend from 1st January 2000 at 00.00 to 31st December 2013 at 23.59, for a total duration of 14 years. The FLEXPART simulations for this work are driven by ECMWF ERA (ECMWF Re-Analysis)-Interim meteorological data: wind speed and direction, temperature and humidity vertical profiles and other variables, with a $1^{\circ} \times 1^{\circ}$ horizontal resolution and at more than 100 vertical levels. The FLEXPART outputs are calculated every 6 hours. They simulate 13 altitude levels from the surface to $12000 \mathrm{~m}$ altitude (vertical resolution of $1 \mathrm{~km}$, except for the lowest layer of $100 \mathrm{~m}$ thickness). The model outputs are taken every 6 hours to account for the daily variability of the meteorological fields. As discussed above, $\mathrm{SO}_{2}$ emission rates are available on a daily interval. Thus, the daily emission data have been oversampled, with the daily value divided by 4 to obtain a pseudo-resolution of 6 hours, for each individual 6-hour computation step. The outputs are 6-hourly distributions of the $\mathrm{SO}_{2}$ profile and total column concentrations in the area.

In addition, the air masses trajectories (centroid of the dispersed plumes) is obtained throughout the period 2000-2013.

\section{Results}

3.1. Quantification of the exposition of the central-southern Mediterranean sector to volcanic air masses originating from Mount Etna

We investigated the average dynamical patterns from Etna, in the selected period, by means of the extended FLEXPART simulations to assess the possible influence on the Southern sector of the central Mediterranean.

Figure 23 shows the distribution of the trajectory ending points in the different sectors, for the trajectories initialised at Mount Etna's summit during the period 2000-2013. Eight sub-quadrants are considered and shown in a wind rose representation. Lampedusa is in the south-western (SW) sub-quadrant, within a 
larger sector (SW, S and SE) that can be identified as central-southern Mediterranean. Trajectories directions after different time intervals (6, 24 and 48 hours) are analysed. For all trajectory durations after initialization, the directions of air masses are predominantly towards E (6 hours: 39.8\%, 24 hours: 40.4\%, 48 hours: $43.3 \%)$, SE (6 hours: 27.8\%, 24 hours: 26.5\%, 48 hours: $24.0 \%$ ) and NE (6 hours: 12.2\%, 24 hours: 11.9\%, 48 hours: 11.9\%). Near $80 \%$ of plumes are then dispersed towards the eastern Mediterranean. The trajectory duration does not substantially impact the directional distribution. The frequency of occurrence of trajectories in the sector of Lampedusa (SW) is relatively small (6 hours: 4.5\%, 24 hours: $4.7 \%, 48$ hours: $5.1 \%$ ).

Figure $2 \mathrm{~b}$ shows the frequency of occurrence of trajectories towards SW, for each year and for 6-, 24- and 48-hour trajectories. This analysis shows that a consistent inter-annual variability exists, with a minimum frequency of about $1 \%$ in 2010, and a maximum of about $7 \%$ in 2000 (24-hour trajectories) and 2012 (48-hour trajectories). In any case, the trajectories towards SW are largely infrequent throughout this time interval.

Figure 3 shows the average Mount Etna's $\mathrm{SO}_{2}$ total column concentration plume between 2000 and 2013, as derived from the $\mathrm{SO}_{2}$ dispersion fields from FLEXPART ( $\mathrm{SO}_{2}$ total column). As already seen from the trajectory analysis of Fig. 2, the dispersion of the volcanic plume is prevailingly directed toward east, north-east and south-east. This is reflected by the average plume of Fig. 3. On average, Lampedusa is in an area of small but existent impact (average $\mathrm{SO}_{2}$ total column concentration from Mount Etna's emission of about $0.04 \mathrm{t}$ $\left.\mathrm{km}^{-2}\right)$.

3.2. Impact of the overpass of air masses from Mount Etna to $\mathrm{SO}_{2}$ concentrations and aerosols average size at Lampedusa

We have set a square area of $1^{\circ} \times 1^{\circ}$ (about $100 \times 100 \mathrm{~km}$ at these latitudes) around Lampedusa and sub-divided the set of FLEXPART trajectories described in Sect. 2.2 in two classes. Class 1 trajectories overpass the area around Lampedusa, while class 2 trajectories do not overpass the area. We 
Trajectory directions $\mathbf{2 0 0 0 - 2 0 1 3 [ \% ] ~}$

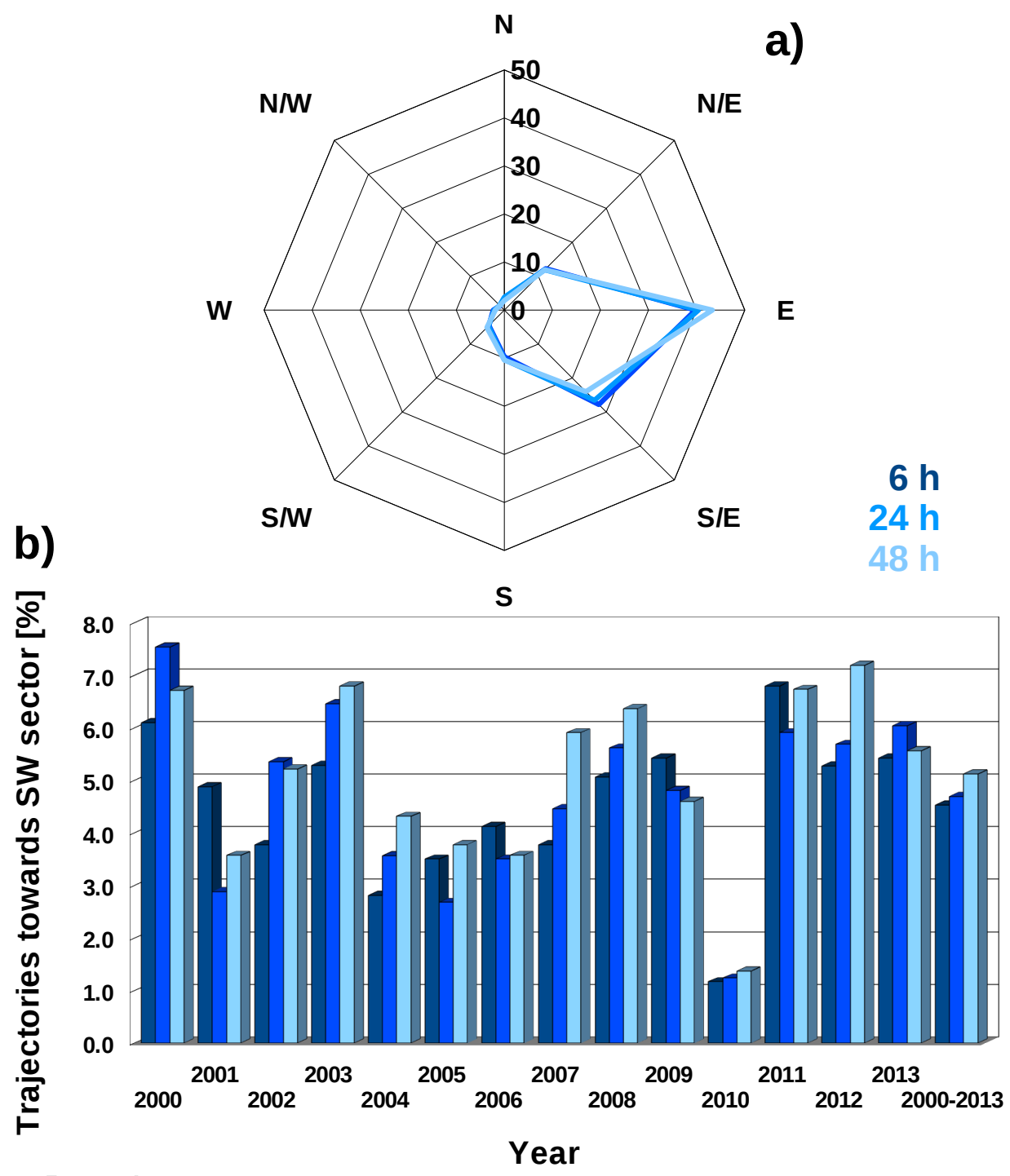

Figure 2: (a) Wind rose representation of the percent frequency of occurrence of air masses trajectories initialised from Mount Etna's summit, in the period 2000-2013; (b) yearly percent frequency of occurrence of trajectories towards south-western sector. Dark, medium and light blue represent 6-, 24- and 48-hours long trajectories, in (a) and (b). 


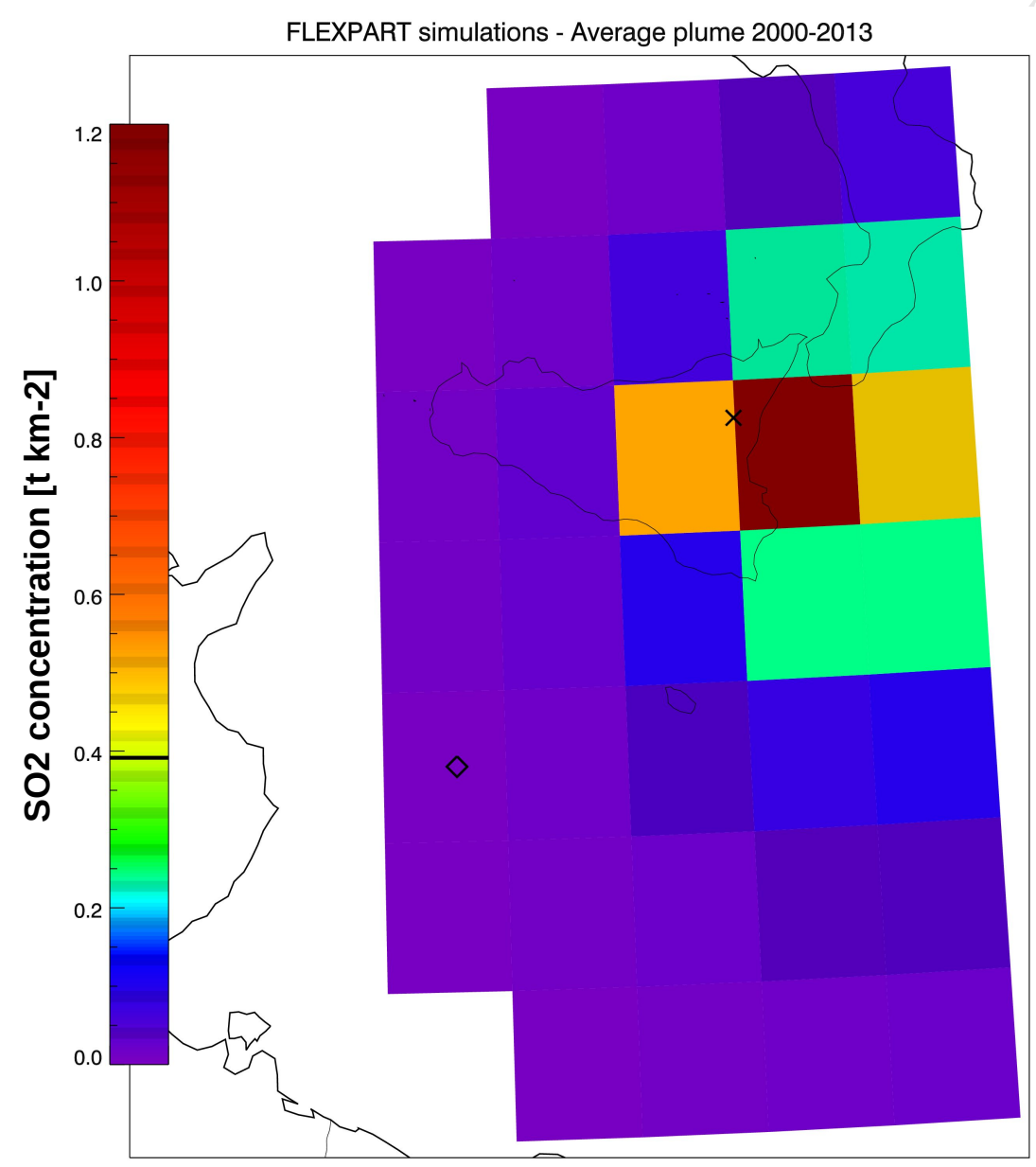

Figure 3: Average $\mathrm{SO}_{2}$ total column concentrations (2000-2013) from FLEXPART plume dispersion simulations. The position of Lampedusa is indicated with a black diamond; the position of Mount Etna is indicated with a black cross. 

port of Etnean volcanic effluents to Lampedusa. This assumption is based on the supposition that the plume arriving in this area is sufficiently wide. For the case of the eruptive activity of fall-winter 2002, Tiesi et al. 41] have shown that at similar distances from Mount Etna's summit craters (a few hundred kilometers) the spread of the plume is consistent with this assumption.

It must be emphasized that Mount Etna produces substantial emissions even during periods of eruptive quiescence, due to summit craters passive degassing. The integrated $\mathrm{SO}_{2}$ emissions during this activity can be important. Thus, an impact on the observations at Lampedusa also during passive degassing periods is possible, although the associated emissions may be small.

Figures 4 and $\mathrm{b}$ show the distributions of daily $\mathrm{SO}_{2}$ anomaly and Ångström exponent observations at Lampedusa, for class 1 (orange) and class 2 (light blue) trajectories. The distributions of the $\mathrm{SO}_{2}$ anomaly and Ångström exponent appear to depend on the trajectory class.

The distributions of the $\mathrm{SO}_{2}$ anomaly values was fitted with a mono-modal Gaussian curve. The mean value is 0.43 DU for class 1, and 0.08 DU for class 2 trajectories. The distribution full width at half maximum (FWHM) is 0.34 DU for class 1, and 0.23 DU for class 2. The two mean values have been found significantly different, as a result of a t-Student test $\left(\mathrm{p}<10^{-6}\right)$. About $10 \%$

of the class 1 cases display $\mathrm{SO}_{2}$ anomalies larger than 1.0 DU. This sub-class (average anomaly of $1.65 \pm 0.51 \mathrm{DU}$ ) has the characteristics of an outliers group. This supports our choice of 1.0 DU as a threshold in $\mathrm{SO}_{2}$ column anomaly, as described in Sect. 2.1.4 This outliers group of data, i.e. a relative maximum of the distributions for large values, is not present in the class 2 distribution.

The distributions of the Ångström exponent values for class 2 trajectories can be fitted with a mono-modal Gaussian curve with mean value of 0.86 and FWHM of 0.38 . The distribution for class 1 cases is more complex and can be fit with a 3 -mode Gaussian function, whose mean values are at 0.51, 1.30 and 1.65, respectively. The FWHM of the three modes are $0.14,0.16$ and 0.27 , 

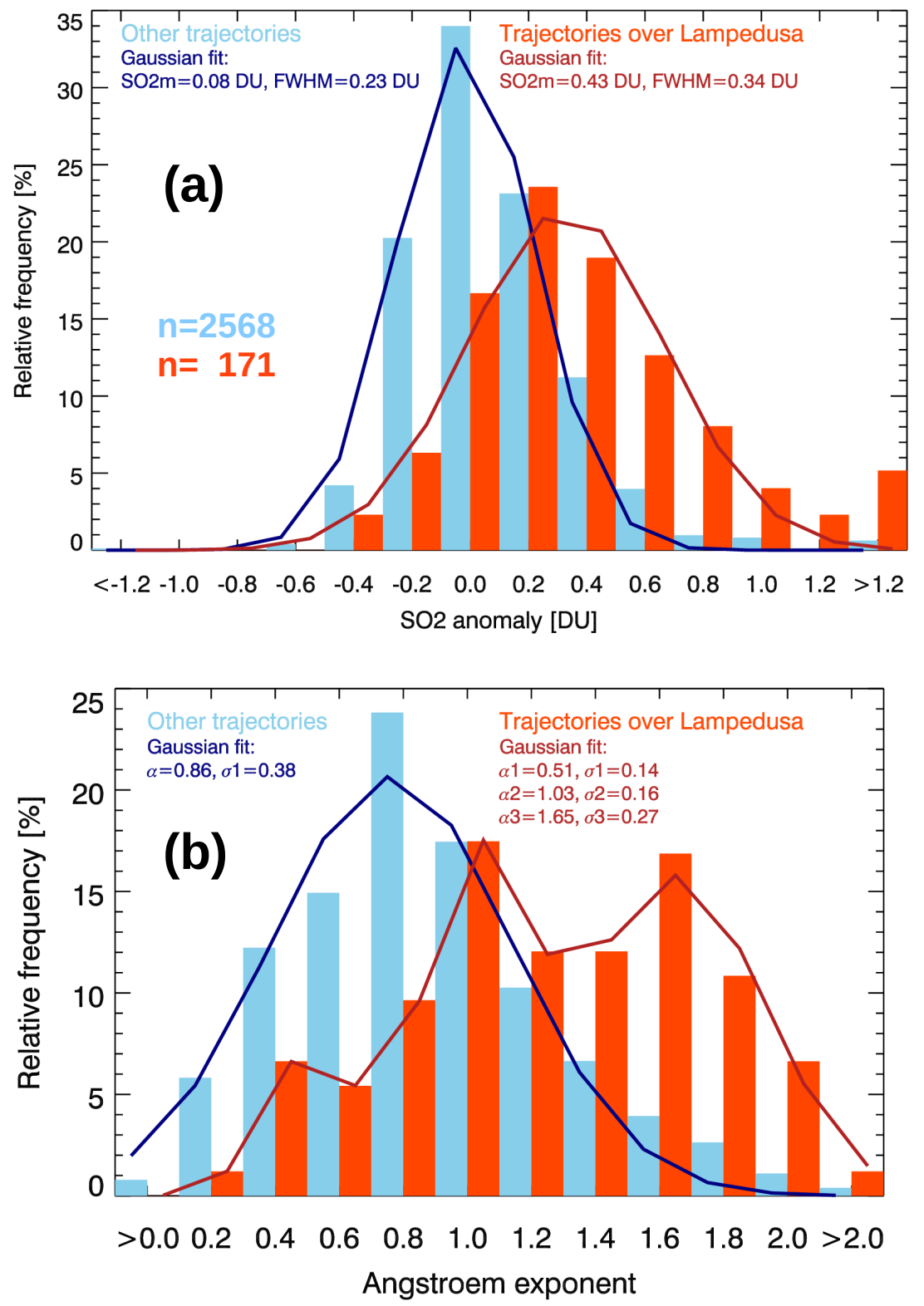

Figure 4: (a) Relative percent frequency of daily $\mathrm{SO}_{2}$ column anomaly and (b) Ångström exponent observations at Lampedusa, for class 1 (trajectories from Etna overpassing Lampedusa, orange), and class 2 (trajectories from Etna non-overpassing Lampedusa, light blue). The number of trajectories in the two classes is indicated in the text (as n). A Gaussian fit is applied to all distributions, and curves and parameters (mean value and full width at half maximum - FWHM) are reported. A fit with a 3-mode Gaussian curve is applied to the distribution of the class 1 Ångström exponent 1 galues. 
by analysing the paths of the individual trajectories. Figure 5 shows the individual class 1 trajectories for values of the Ångström exponent larger than 1.4, between 0.6 and 1.4, and smaller than 0.6. The average trajectory and its spread (defined as the standard deviation of the longitude/latitude values of the trajectories at the same timestamp) is also shown for the three Angström exponent ranges of values. An increasing spread of the trajectories for decreasing values of the Ångström exponent is apparent. This indicates that more direct (pure volcanic) trajectories are associated with aerosol layers with smaller particles at Lampedusa. On the contrary, mixing with other aerosol types, such as marine, in some cases desert dust, biomass burning, or others, along more complex paths may contribute for the cases of intermediate and small values of the Ångström exponent. Intermediate values of the Ångström exponent for mixed aerosol layers are also found and discussed by Pace et al. [19]. The enhanced occurrence of values of $\alpha$ larger than 1.4 is not present in the class 2 distribution.

3.3. Potential of air masses from Mount Etna to cause $\mathrm{SO}_{2}$ and Ångström exponent exceedances at Lampedusa

The previous analysis suggests that volcanic air masses originating from Mount Etna's summit and reaching Lampedusa display some peculiar distributions in the $\mathrm{SO}_{2}$ column anomaly and Ångström exponent. We now look at the impact of Mount Etna's plume on the exceedences of these two parameters, as defined in Sect. 2.1.4.

Figures $1 \mathrm{~b}$ and $\mathrm{c}$ show the time series of $\mathrm{SO}_{2}$ anomaly (Fig. 1 $\mathrm{b}$ ) and Ångström exponent observations (Fig. 1) at Lampedusa, from 2000 to 2013, with exceedences (red crosses) and class 1 days in evidence (blue diamonds). It is visually apparent how exceedances are more probable for the class 1 cases (higher density of blue squares matching red than black crosses). We quantify this coincidence by calculating the conditional probability of exceedances in class $1 \mathbf{P}$ (exc|ovp), and comparing this quantity with the a priori probability of exceedance $\mathbf{P}(\mathrm{exc})$. For the two variables $\left(\mathrm{SO}_{2}\right.$ anomaly and $\left.\alpha\right)$, the two 

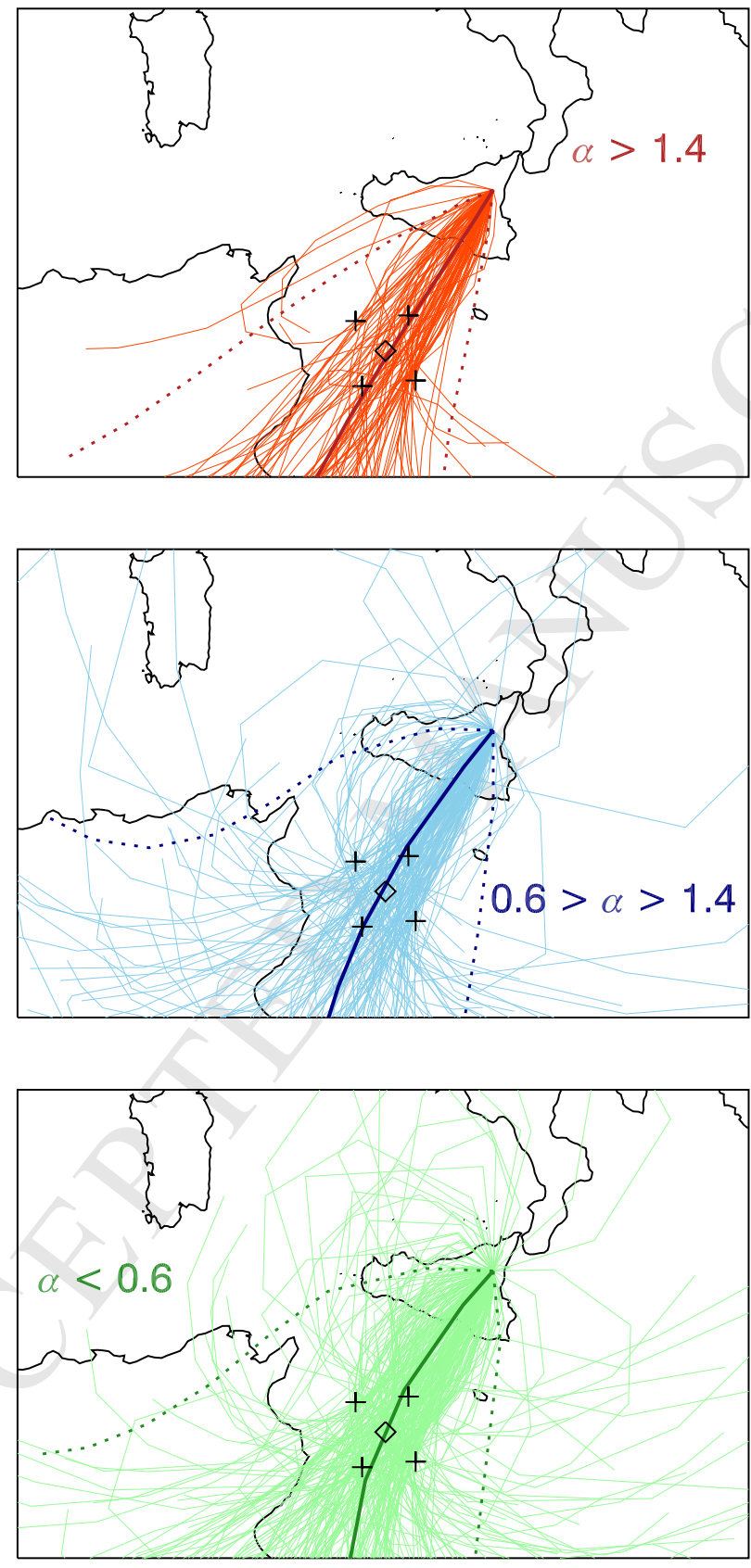

Figure 5: Individual air masses trajectories for the days with Ångström exponent values at Lampedusa larger than 1.4 (top, orange), between 0.6 and 1.4 (middle, light blue), and smaller than 0.6 (bottom, light green). The average trajectory (thick solid lines) and the variability in terms of the standard deviation of the coordinates (thick dotted lines) for each ensemble of trajectories is also shown. The position of Lampedusa is indicated with a black diamond; the $1^{\circ} \times 1^{\circ}$ area selected to identify the class 1 trajectories (overpassing Lampedusa) is marked by the 4 black crosses. 
Table 1: Percent conditional probabilities of exceedances in overpassing situations $\mathbf{P}$ (exc|ovp) and percent a priori probability of exceedance $\mathbf{P}(\mathrm{exc})$, for the two variables var $=\left(\mathrm{SO}_{2}\right.$ anomaly, $\alpha)$.

\begin{tabular}{lcc}
\hline var & $\mathbf{P}_{\text {var }}($ exc) $[\%]$ & $\mathbf{P}_{\text {var }}($ exc $\mid$ ovp $)[\%]$ \\
\hline $\mathrm{SO}_{2}$ & 2.0 & 10.6 \\
$\alpha$ & 16.5 & 42.1 \\
\hline
\end{tabular}

probabilities are calculated as follows:

$$
\begin{array}{ll}
\mathbf{P}_{\mathrm{var}}(\text { exc } \mid \text { ovp }) & =\frac{\text { no. of exceedances in class } 1}{\text { no. of class } 1 \text { cases }} \\
\mathbf{P}_{\mathrm{var}}(\mathrm{exc}) & =\frac{\text { no. of exceedances }}{\text { no. of observations }}
\end{array}
$$

The probabilities are summarized in Table 1. The probability of having $\mathrm{SO}_{2}$ and Ångström exponent exceedance at Lampedusa is about 5 and 3 times larger, respectively, when air masses who travelled over Mount Etna overpass Lampedusa than in the general conditions. The probability of $\alpha$ exceeding the threshold value for Etnean air masses is higher than $40 \%$. The probabilities are smaller for the $\mathrm{SO}_{2}$ anomaly because of the smaller sensitivity of $\mathrm{SO}_{2}$ Brewer observations and the relatively high detection threshold.

We further investigate the conditional probability to have exceedances during overpass events, by calculating $\mathbf{P}$ (exc|ovp, lag) with different time lags. Figure 6 shows these quantities as a function of the time lag, for the two observed variables. The values at zero time lag (exceedance during the same day of the overpass) are the same of Table 1, and are found to correspond with maxima with respect to the time lag. This is consistent with the estimated travel time from Etna to Lampedusa. For time lags greater than 0 (exceedance found $\mathrm{x}$ days after the overpass), $\mathbf{P}($ exc|ovp, lag $=\mathrm{x})$ is smaller. For the $\mathrm{SO}_{2}$ anomaly, the probability smoothly decreases for increasing lag, approaching values very close to the a priori $\mathbf{P}_{\mathrm{SO} 2}$ (exc) at lags greater than about 7-10 days. It must be however pointed out that the present analysis is based on daily values, and that all observations are based on measurements of solar radiation and carried 


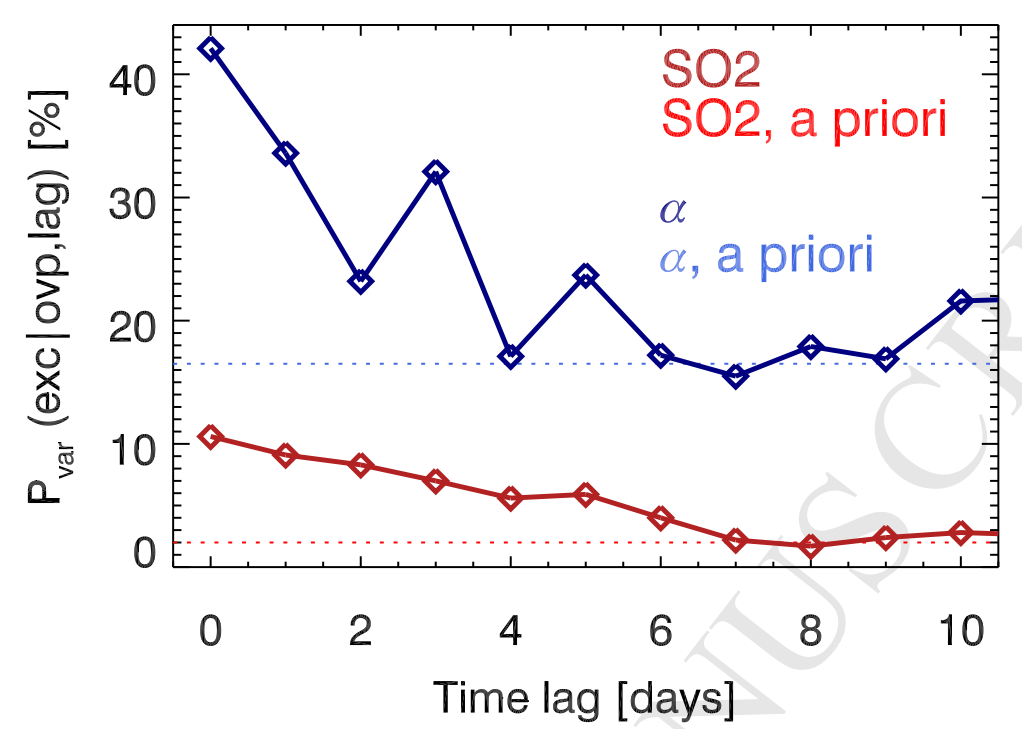

Figure 6: Percent conditional probabilities of exceedances for class 1 trajectories $\mathbf{P}$ (exc|ovp, lag) as a function of the time lag (in days). Sulfur dioxide anomaly and Ångström exponent observations at Lampedusa are in dark red and blue, respectively. The a priori probabilities of exceedances $\mathbf{P}(\mathrm{exc})$ are also shown in light red and blue dotted line.

out in daytime. Thus, lags shorter than 10-12 hours are classified as zero in this analysis. The behaviour of $\mathbf{P}_{\alpha}$ (exc|ovp, lag) is more complex than for the $\mathrm{SO}_{2}$ anomaly. As for the $\mathrm{SO}_{2}$ anomaly, the maximum occurs for zero time lag, and the probability gets close to $\mathbf{P}_{\alpha}(\mathrm{exc})$ for time lags longer than 6-7 days. Two relative maxima are found at time lags of 3 and 5 days. This is peculiar of this variable and could suggest different gas-to-particle or aerosol evolution processes, e.g., different aerosol nucleation pathways or different sinks, with maxima of the efficiency for different time intervals along transport. This behaviour requires additional verification and investigation.

To summarize, we have found that the Etnean air masses' origins are, locally at Lampedusa, a statistically significant factor contributing to elevated values of $\mathrm{SO}_{2}$, and to small aerosol particles. The maximum influence is found on the same day of the Etna overpass, while smaller relative maxima of the $\alpha$ exceedance probability are found at time lags of 3 and 5 days. The long-term (lags 
longer than about 7 days) behaviour of the exceedance probabilities, showing a convergence to a priori values, suggests a possible causal effect between the overpass event and local exceedance of the $\mathrm{SO}_{2}$ anomaly and $\alpha$.

\subsection{The role of the Mount Etna's emission strength}

The intensity of $\mathrm{SO}_{2}$ emission from Etna is expected to influence measurements at Lampedusa. Figure 7 shows the mean values of the $\mathrm{SO}_{2}$ anomaly and $\alpha$ at Lampedusa in different conditions, depending on the class and on the corresponding $\mathrm{SO}_{2}$ emission rate at the Etna. In particular, we show the mean values for: 1) all class 2 conditions, 2) all class 1 conditions, 3) subsets of the class 1 cases, grouped for fixed lower limits of the $\mathrm{SO}_{2}$ emission rate. Emission limits of 20,30,40, and $50 \mathrm{~kg} \mathrm{~s}^{-1}$ are considered. Although peak $\mathrm{SO}_{2}$ emission rates (ER) during the 2000-2013 period reached $250 \mathrm{~kg} \mathrm{~s}^{-1}$, the average and the maximum emission rate for class 1 cases are $20.6 \pm 13.1 \mathrm{~kg} \mathrm{~s}^{-1}$ and $72.4 \mathrm{~kg}$ $\mathrm{s}^{-1}$ (this latter rate on 3 August 2001), respectively. In fact, Lampedusa was not reached by trajectories from Etna during the strongest paroxystic volcanic activity in the period 2000-2013.

Although extreme $\mathrm{SO}_{2}$ emission rate values for class 1 are lacking, a small increase of $\alpha$ for ER larger than $50 \mathrm{~kg} \mathrm{~s}^{-1}$, and more marked increase of the $\mathrm{SO}_{2}$ anomaly for ER larger than 40 and $50 \mathrm{~kg} \mathrm{~s}^{-1}$, is apparent in Fig. 7.

As expected from the previous analysis, the mean values of the $\mathrm{SO}_{2}$ anomaly and $\alpha$ for class 1 cases $\left(\mathrm{SO}_{2}\right.$ anomaly: $\left.0.43 \pm 0.34, \alpha: 1.06 \pm 0.47\right)$ are higher than for class $2\left(\mathrm{SO}_{2}\right.$ anomaly: $\left.0.08 \pm 0.23, \alpha: 0.86 \pm 0.38\right)$. The $\mathrm{SO}_{2}$ anomaly and $\alpha$ of class 1 cases do not appear to depend on the emission rate for ER lower than $40 \mathrm{~kg} \mathrm{~s}^{-1}$. Conversely, class 1 averages of the $\mathrm{SO}_{2}$ anomaly and $\alpha$ for ER larger than 40 and $50 \mathrm{~kg} \mathrm{~s}^{-1}$ are larger than the averages over the whole class 1 dataset (i.e., average over all values of ER).

Dynamical processes, partly also depending on the emission altitude, are expected to play a very important role driving the progressive spatial diffusion of the plume, For small and moderate eruptions the dynamical evolution of the plume may be considered the dominant factor determining the amount of gases 


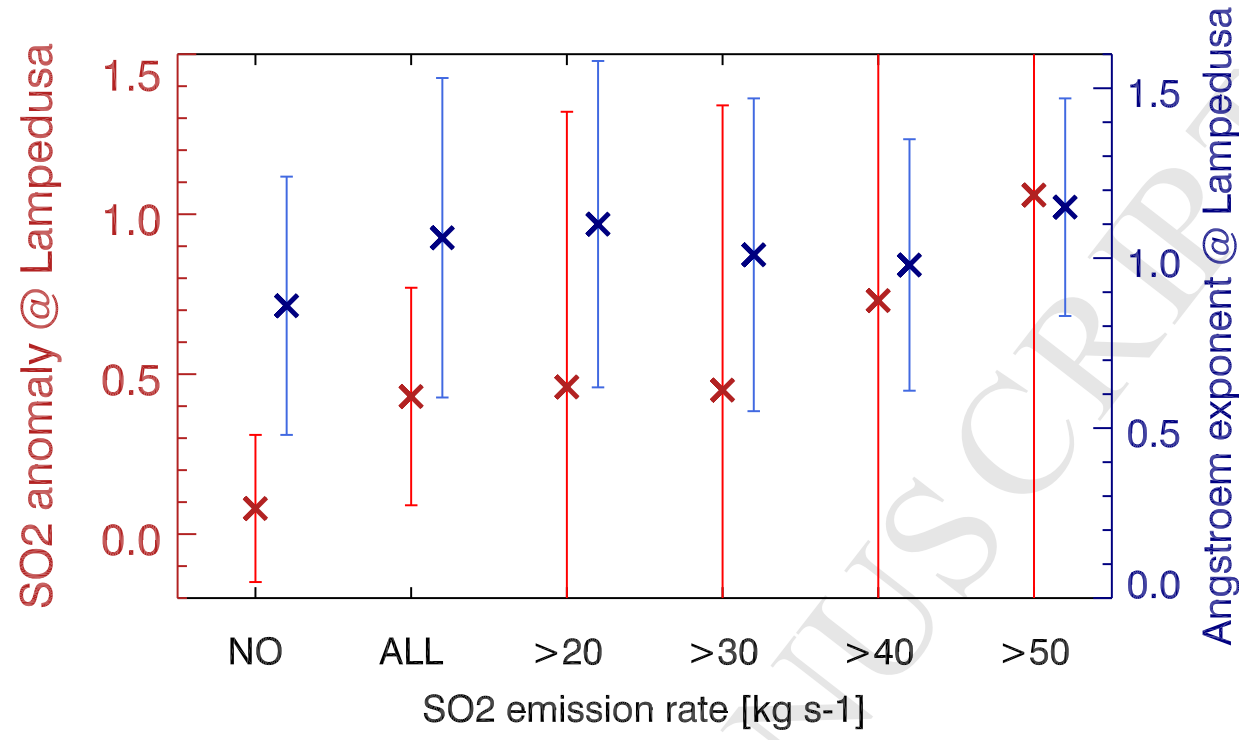

Figure 7: Mean $\mathrm{SO}_{2}$ anomaly (blue crosses and one-standard-deviation error bars) and $\alpha$ (red crosses and one-standard-deviation error bars) for Etnean air masses not overpassing Lampedusa (NO, class 2 trajectories), all overpasses (ALL, class 1 trajectories) and overpasses with fixed lower limit for the $\mathrm{SO}_{2}$ emission rate $\left(>20,>30,>40\right.$ and $\left.>50 \mathrm{~kg} \mathrm{~s}^{-1}\right)$.

and particles reaching a specific fixed observation point. It is likely that events characterized by very large emissions may produce more evident effects, which are possibly less dependent on the dynamics than for smaller emissions.

Consistently with this scenario, the dynamical pattern driving aimasses from Etna to Lampedusa seems to play a more important role than the intensity of $\mathrm{ER}$, at least for small and moderate $\mathrm{SO}_{2}$ emissions. This is consistent with the individual case study of Sellitto et al. 14. This conclusion is possibly specific for Lampedusa and its exposition to Etnean air masses. The limited correlation between near source emission rates and downwind $\mathrm{SO}_{2}$ and aerosol parameters might not be true for other Mediterranean sectors, more exposed to Etnean 475 plumes during explosive eruptions. 


\subsection{Quantification of the downwind impact of Mount Etna at Lampedusa}

The previous analyses were aimed at investigating if Mount Etna's sulfur emissions produce a statistically significant impact on the magnitude and the occurrence of $\mathrm{SO}_{2}$ anomaly and $\alpha$ exceedances at Lampedusa. Once demonstrated that an impact exists, we finally quantify this impact by estimating how many $\mathrm{SO}_{2}$ and $\alpha$ exceedances at Lampedusa are caused by Mount Etna's sulfur emissions. To do this, we have calculated the probability that an overpass has caused a given threshold exceedance, $\mathbf{P}$ (ovp|exc), as follows:

$$
\mathbf{P}(\text { ovp } \mid \text { exc })=\frac{\text { no. of exceedances in class } 1}{\text { no. of exceedances }}
$$

In other words, we identify each exceedance which is coincident with an oversimultaneous $\mathrm{SO}_{2}$ anomaly and $\alpha$ exceedances have been found, with 5 cases in 2006. 
The small number of simultaneous exceedances may be attributed to two reasons. First, the aerosol phenomenology in this area is intrinsically complex. Notably, the possible occurrence and mixing of different aerosol types at different altitudes along the trajectory is expected to be particularly important. In the Mediterranean the aerosol vertical distribution may be complex, with layers with markedly different optical properties at different altitudes. This complex vertical structure has been observed in previous studies also at Lampedusa, e.g., [42, 43, 44]. For example, the presence of marine particles, which are obviously the dominant aerosol type measured in the lower troposphere at Lampedusa, see, e.g., [16, leads to a reduction of the column Ångström exponent. A large influence of marine particles is expected particularly during episodes with strong winds close to the surface, see, e.g., [45]. The strong low level winds are not expect to directly affect the $\mathrm{SO}_{2}$ column anomalies, since the emission altitude generally leads to a plume travelling in the mid- and high troposphere. This is just one example of the mentioned complexity and future studies are necessary to simultaneously analyse the different aerosol sources and processes in the area, including volcanic emissions. Second reason for the small number of simultaneous exceedances is the relatively high detection limit of the Brewer column $\mathrm{SO}_{2}$ observations and the potential limited vertical extent of the volcanic $\mathrm{SO}_{2}$ perturbations. This limits the number of the overall (volcanic plus non-volcanic origins) detections of $\mathrm{SO}_{2}$ anomaly exceedances, which indeed is sensibly smaller than the detections of $\alpha$ exceedances ( 65 versus 511, see Table 2). The small number of the overall detections of the $\mathrm{SO}_{2}$ anomaly exceedances obviously limits the number of simultaneous $\mathrm{SO}_{2}$ and $\alpha$ exceedances detections.

We quantify the total impact of Mount Etna at Lampedusa during the investigation period by calculating what proportion of the total threshold exceedances can be attributed to the volcano. These are $38 \%$ of the $\mathrm{SO}_{2}$ anomaly exceedances ( 25 cases out of a total of 65 exceedances) and $20 \%$ of the $\alpha$ exceedances (103 cases out of the total of 511 exceedances). It is worth noticing that these impact estimations are about 4 to 8 times greater than the average fraction of transport events towards Lampedusa (about 5\%, see Sect. 3.1). This 
a further evidence of the likely causal impact of Mount Etna's sulfur emissions on $\mathrm{SO}_{2}$ column anomaly and aerosol properties.

The days of $\mathrm{SO}_{2}$ and $\alpha$ exceedances, as well as the days of simultaneous exceedances, which are attributed to the transport of Mount Etna's effluents (Table 2) are available as Supplementary Material.

Table 2: Percent conditional probabilities of exceedances due to class 1 air masses $\mathbf{P}_{\text {var }}$ (ovp/exc), for the $\mathrm{SO}_{2}$ anomaly and $\alpha$, and number of simultaneous $\mathrm{SO}_{2}$ column anomaly and $\alpha$ exceedances. The quantities are reported for individual years and the whole 2000-2013 period.

\begin{tabular}{cccc}
\hline Year & $\mathbf{P}_{\mathrm{SO} 2}($ ovp $\mid$ exc $)$ & $\mathbf{P}_{\alpha}($ ovp $\mid$ exc $)$ & Simultaneous $\mathrm{SO}_{2}$ and $\alpha$ exceedances \\
\hline 2000 & $29.4 \%(5 / 17)$ & $16.7 \%(5 / 30)$ & 1 \\
2001 & $50.0 \%(1 / 2)$ & $66.7 \%(2 / 3)$ & 1 \\
2002 & $28.6 \%(2 / 7)$ & $25.0 \%(6 / 24)$ & \\
2003 & $0.0 \%(0 / 1)$ & $25.9 \%(15 / 58)$ & \\
2004 & $-(0 / 0)$ & $9.7 \%(3 / 31)$ & \\
2005 & $-(0 / 0)$ & $14.6 \%(6 / 41)$ & \\
2006 & $66.7 \%(6 / 9)$ & $18.9 \%(10 / 53)$ & 1 \\
2007 & $33.3 \%(1 / 3)$ & $38.9 \%(7 / 18)$ & \\
2008 & $50.0 \%(1 / 2)$ & $15.7 \%(8 / 51)$ & \\
2009 & $50.0 \%(1 / 2)$ & $21.1 \%(4 / 19)$ & 2 \\
2010 & $-(0 / 0)$ & $11.1 \%(3 / 27)$ & \\
2011 & $50.0 \%(5 / 10)$ & $24.5 \%(12 / 49)$ & \\
2012 & $25.0 \%(1 / 4)$ & $21.3 \%(10 / 47)$ & \\
2013 & $33.3 \%(2 / 6)$ & $20.0 \%(12 / 60)$ & \\
\hline $2000-2013$ & $38.5 \%(25 / 65)$ & $20.2 \%(103 / 511)$ & \\
\hline
\end{tabular}

\section{Conclusions}

In this paper, the downwind impact of Mount Etna's sulfur emissions in the central Mediterranean is estimated over the period 2000- 2013 using long-term 
series of daily $\mathrm{SO}_{2}$ emission rates measured near crater at Mount Etna with ground-based ultraviolet spectrophotometers, Lagrangian dispersion and trajectory simulations and downwind column $\mathrm{SO}_{2}$ and aerosol Ångström exponent observations at Lampedusa. The south-western sector, where Lampedusa is located, is downwind Mount Etna during only 4.5-5.0\% of the trajectories, thus indicating that this sector of the Mediterranean is infrequently reached by air masses containing volcanic effluents. Nevertheless, several indications suggest that a statistically significant impact of Mount Etna's sulfur emissions on the $\mathrm{SO}_{2}$ concentrations (as shown by the $\mathrm{SO}_{2}$ total column anomaly) and aerosol microphysical properties (as shown by the Angström exponent $\alpha$ ), exists. We grouped in class 1 all trajectories, and the corresponding measurement days, reaching Lampedusa and originating from the Etna summit, and in class 2 all the other days. Sulfur dioxide columns anomalies are found about $80 \%$ higher (0.43 DU versus $0.08 \mathrm{DU}$, difference significant from a t-Student test) for class 1 than for class 2 cases. The Ångström exponent daily values display different distributions for class 1 and for class 2 trajectories: a 3-mode Gaussian distribution, with a distinct maximum at large $\alpha$ values (about 1.65), is found for class 1 , while a mono-modal Gaussian distribution, with a maximum at moderate $\alpha$ values (about 0.85 ) is found for class 2. Compared to background conditions, Mount Etna's plume overpasses are found to cause an increase in the likelihood of $\mathrm{SO}_{2}$ anomaly and $\alpha$ threshold exceedances (about $10.6 \%$ versus $2.0 \%$, and about $45 \%$ versus $15 \%$, i.e. 5 and 3 times larger, for the $\mathrm{SO}_{2}$ anomaly and $\alpha$, respectively). While the prevailing dynamics seems crucial to determine the impact on the observations at Lampedusa, the magnitude of the $\mathrm{SO}_{2}$ emission rates seems to play a smaller role, at least for small and moderate emissions. The impact of the emission rate is stronger on the downwind $\mathrm{SO}_{2}$ anomalies than on $\alpha$. Nevertheless, it should be noted that Lampedusa was not downwind Mount Etna during the strongest paroxystic eruptive events in the period under investigation. Finally, it has been estimated that about $40 \%$ and $20 \%$ of the $\mathrm{SO}_{2}$ anomaly and $\alpha$ exceedances at Lampedusa could be attributed to Mount Etna's sulfur emissions. 


\section{Acknowledgments}

FLEXPART has been developed at NILU - Norwegian Institute for Air Research. Measurements at Lampedusa were partially supported by the Italian Ministry for University and Research through the NextData Project. Francesco Monteleone and Damiano Sferlazzo guaranteed the continuity of the observations at Lampedusa, and their contribution is gratefully acknowledged. This work has been partially supported by the EU 7th Framework Program under the grants 603557 (StratoClim) and 308665 (Med-SuV), and by the Istituto Nazionale di Geofisica e Vulcanologia under the grant SMED (Sulfur MEditerranean Dispersion).

\section{References}

[1] R. von Glasow, N. Bobrowski, C. Kern, The effects of volcanic eruptions on atmospheric chemistry, Chemical Geology 263 (14) (2009) 131 - 142. doi:http://dx.doi.org/10.1016/j.chemgeo.2008.08.020.

[2] S. Gassó, Satellite observations of the impact of weak volcanic activity on marine clouds, Journal of Geophysical Research: Atmospheres 113 (D14S19) (2008) n/a-n/a. doi:10.1029/2007JD009106.

口 [3] U. Lohmann, B. Kärcher, C. Timmreck, Impact of the Mount Pinatubo a eruption on cirrus clouds formed by homogeneous freezing in the ECHAM4 GCM, Journal of Geophysical Research: Atmospheres 108 (D18), 4568. doi:10.1029/2002JD003185

URL http://dx.doi.org/10.1029/2002JD003185

[4] A. Robock, C. Oppenheimer, Volcanism and the Earth's Atmosphere, Vol. 139 of Geophysical Monograph Series, American Geophysical Union, 2003.

[5] M. P. McCormick, L. W. Thomason, C. R. Trepte, Atmospheric effects of the Mt Pinatubo eruption, Nature 373 (1995) 399-404. doi:10.1038/ 373399a0, 
[6] P. Hamill, E. J. Jensen, P. B. Russell, B. J. J., The Life Cycle of Stratospheric Aerosol Particles, Bulletin of the American Meteorological Society 78 (7) (1997) 13951410. doi:http://dx.doi.org/10.1175/ 1520-0477(1997)078<1395:TLCOSA>2.0.C0;2.

[7] A. Robock, The Climatic Aftermath, Science 295 (5558) (2002) 1242-1244. doi:10.1126/science.1069903.

[8] J. Wang, S. Park, J. Zeng, C. Ge, K. Yang, S. Carn, N. Krotkov, A. H. Omar, Modeling of 2008 Kasatochi volcanic sulfate direct radiative forcing: assimilation of $\mathrm{OMI} \mathrm{SO}_{2}$ plume height data and comparison with MODIS and CALIOP observations, Atmospheric Chemistry and Physics 13 (4) (2013) 1895-1912. doi:10.5194/acp-13-1895-2013.

[9] F. Jégou, G. Berthet, C. Brogniez, J.-B. Renard, P. François, J. M. Haywood, A. Jones, Q. Bourgeois, T. Lurton, F. Auriol, S. Godin-Beekmann, C. Guimbaud, G. Krysztofiak, B. Gaubicher, M. Chartier, L. Clarisse, C. Clerbaux, J. Y. Balois, C. Verwaerde, D. Daugeron, Stratospheric aerosols from the Sarychev volcano eruption in the 2009 Arctic summer, Atmospheric Chemistry and Physics 13 (13) (2013) 6533-6552. doi: 10.5194/acp-13-6533-2013

[10] M. J. M. Penning de Vries, S. Dörner, J. Pute, C. Hörmann, M. D. Fromm, T. Wagner, Characterisation of a stratospheric sulfate plume from the

1. Nabro volcano using a combination of passive satellite measurements in nadir and limb geometry, Atmospheric Chemistry and Physics 14 (15) (2014) 8149-8163. doi:10.5194/acp-14-8149-2014. URL http://www . atmos-chem-phys .net/14/8149/2014/

[11] M. R. Burton, G. M. Sawyer, D. Granieri, Deep carbon emissions from volcanoes, Reviews in Mineralogy and Geochemistry 75 (1) (2013) 323354. doi:10.2138/rmg.2013.75.11

[12] H.-F. Graf, J. Feichter, B. Langmann, Volcanic sulfur emissions: Estimates of source strength and its contribution to the global sulfate distribution, 
Journal of Geophysical Research 102 (D9) (1997) 10727-10738. doi:10. 1029/96JD03265.

[13] D. S. Stevenson, C. E. Johnson, W. J. Collins, R. G. Derwent, The tropospheric sulphur cycle and the role of volcanic SO2, Geological Society, London, Special Publications 213 (1) (2003) 295-305. doi:10.1144/GSL. SP. 2003.213.01.18

[14] P. Sellitto, A. di Sarra, S. Corradini, M. Boichu, H. Herbin, P. Dubuisson, G. Sèze, D. Meloni, F. Monteleone, L. Merucci, J. Rusalem, G. Salerno, P. Briole, B. Legras, Synergistic use of Lagrangian dispersion and radiative transfer modelling with satellite and surface remote sensing measurements for the investigation of volcanic plumes: the Mount Etna eruption of 2527 October 2013, Atmospheric Chemistry and Physics 16 (11) (2016) 68416861. doi:10.5194/acp-16-6841-2016 URL http://www . atmos-chem-phys.net/16/6841/2016/

[15] P. Sellitto, P. Briole, On the radiative forcing of volcanic plumes: modelling the impact of Mount Etna in the Mediterranean, Annals of Geophysics 58 (0) (2015). doi:10.4401/ag-6879.

[16] G. Calzolai, S. Nava, F. Lucarelli, M. Chiari, M. Giannoni, S. Becagli, R. Traversi, M. Marconi, D. Frosini, M. Severi, R. Udisti, A. di Sarra, G. Pace, D. Meloni, C. Bommarito, F. Monteleone, F. Anello, D. M. Sferlazzo, Characterization of $\mathrm{PM}_{10}$ sources in the central Mediterranean, Atmospheric Chemistry and Physics 15 (24) (2015) 13939-13955. doi: 10.5194/acp-15-13939-2015

URL http://www . atmos-chem-phys.net/15/13939/2015/

[17] S. Becagli, D. M. Sferlazzo, G. Pace, A. di Sarra, C. Bommarito, G. Cal655 zolai, C. Ghedini, F. Lucarelli, D. Meloni, F. Monteleone, M. Severi, R. Traversi, R. Udisti, Evidence for heavy fuel oil combustion aerosols from chemical analyses at the island of Lampedusa: a possible large role of ships emissions in the Mediterranean, Atmospheric Chemistry and Physics 
12 (7) (2012) 3479-3492. doi:10.5194/acp-12-3479-2012.

[21] R. Stoiber, L. L. Malinconico, S. N. Williams, Forecasting volcanic events, Elsevier, Amsterdam, 1983, Ch. Use of the correlation spectrometer at volcanoes, pp. 425-444.

[22] T. Caltabiano, R. Romano, G. Budetta, SO2 flux measurements at Mount

[23] B. Galle, C. Oppenheimer, A. Geyer, A. J. McGonigle, M. Edmonds, L. Horrocks, A miniaturised ultraviolet spectrometer for remote sensing of SO2 fluxes: a new tool for volcano surveillance, Journal of Volcanol685

[18] G. Pace, D. Meloni, A. di Sarra, Forest fire aerosol over the Mediterranean basin during summer 2003, Journal of Geophysical Research: Atmospheres 110 (D21202) (2005). doi:10.1029/2005JD005986.

URL http://dx.doi.org/10.1029/2005JD005986

[19] G. Pace, A. di Sarra, D. Meloni, S. Piacentino, P. Chamard, Aerosol optical properties at Lampedusa (Central Mediterranean). 1. Influence of transport and identification of different aerosol types, Atmospheric Chemistry and Physics 6 (3) (2006) 697-713. doi:10.5194/acp-6-697-2006.

URL http://wWw . atmos-chem-phys .net/6/697/2006/

20] G. Pace, W. Junkermann, L. Vitali, A. di Sarra, D. Meloni, M. Cacciani, G. Cremona, A. M. Iannarelli, G. Zanini, On the complexity of the boundary layer structure and aerosol vertical distribution in the coastal Mediterranean regions: a case study, Tellus B 67 (0) (2015).

URL http://www.tellusb.net/index.php/tellusb/article/view/ 27721 Etna (Sicily), Journal of Geophysical Research: Atmospheres 99 (D6) (1994) 12809-12819. doi:10.1029/94JD00224. ogy and Geothermal Research 119 (14) (2003) 241 - 254. doi:http: //dx.doi.org/10.1016/S0377-0273(02)00356-6. 
[24] A. J. S. McGonigle, C. Oppenheimer, A. R. Hayes, B. Galle, M. Edmonds, T. Caltabiano, G. Salerno, M. Burton, T. A. Mather, Sulphur dioxide fluxes from Mount Etna, Vulcano, and Stromboli measured with an automated scanning ultraviolet spectrometer, Journal of Geophysical Research: Solid Earth 108 (B9) (2003)), 2455. doi:10.1029/2002JB002261.

[25] G. Salerno, M. Burton, C. Oppenheimer, T. Caltabiano, D. Randazzo, N. Bruno, V. Longo, Three-years of SO2 flux measurements of Mt. Etna using an automated UV scanner array: Comparison with conventional traverses and uncertainties in flux retrieval, Journal of Volcanology and Geothermal Research 183 (12) (2009) 76-83. doi:http://dx.doi.org/ 10.1016/j.jvolgeores.2009.02.013.

[26] G. Salerno, M. Burton, C. Oppenheimer, T. Caltabiano, V. Tsanev, N. Bruno, Novel retrieval of volcanic SO2 abundance from ultraviolet spectra, Journal of Volcanology and Geothermal Research 181 (12) (2009) 141 - 153. doi:http://dx.doi.org/10.1016/j.jvolgeores.2009.01.009

[27] M. Doukas, A new method for GPS-based wind speed determinations during airborne volcanic plume measurements, Tech. rep., U.S. Geol. Surv. Open-File Rep 02-395 (2002).

[28] U. Platt, J. Stutz, Differential Optical Absorption Spectroscopy: Principles and Applications, Physics of Earth and Space Environments, Springer Berlin Heidelberg, 2008.

URL https://books.google.fr/books?id=y90g9yF1QncC

[29] J. B. Kerr, C. T. McElroy, D. I. Wardle, R. A. Olafson, W. F. J. Evans, Atmospheric Ozone, 1985, Ch. The automated Brewer spectrophotometer, pp. $396-401$.

[30] A. Georgoulias, D. Balis, M. Koukouli, C. Meleti, A. Bais, C. Zerefos, A study of the total atmospheric sulfur dioxide load using ground-based measurements and the satellite derived Sulfur Dioxide Index, Atmospheric 
Environment 43 (9) (2009) 1693 - 1701. doi:http://dx.doi.org/10. $1016 / \mathrm{j}$.atmosenv.2008.12.012.

[31] M. Antón, V. E. Cachorro, J. M. Vilaplana, C. Toledano, N. A. Krotkov,

10.5194/acp-10-5979-2010.

URL http://wWw . atmos-chem-phys .net/10/5979/2010/

[32] P. Sellitto, A. di Sarra, A. M. Siani, An improved algorithm for the de725 tarmination of aerosol optical depth in the ultraviolet spectral range from Brewer spectrophotometer observations, Journal of Optics A: Pure and Applied Optics 8 (10) (2006) 849.

URL http://stacks .iop.org/1464-4258/8/i=10/a=005

[33] A. di Sarra, D. Fua, M. Cacciani, T. D. Iorio, P. Disterhoft, D. Mel${ }_{730}^{\square}$ oni, F. Monteleone, S. Piacentino, D. Sferlazzo, Determination of ultraa violet cosine-corrected irradiances and aerosol optical thickness by com-

a bined measurements with a brewer spectrophotometer and a multifilter rotating shadowband radiometer, Applied Optics 47 (33) (2008) 6142-6150. doi:10.1364/A0.47.006142 URL http://ao.osa.org/abstract.cfm?URI=ao-47-33-6142

[34] A. di Sarra, D. Sferlazzo, D. Meloni, F. Anello, C. Bommarito, S. Corradini, L. D. Silvestri, T. D. Iorio, F. Monteleone, G. Pace, S. Piacentino, S. Pugnaghi, Empirical correction of multifilter rotating shadowband radiometer (MFRSR) aerosol optical depths for the aerosol forward scattering and development of a long-term integrated MFRSR-Cimel dataset at Lampedusa, Appl. Opt. 54 (10) (2015) 2725-2737. doi:10.1364/A0.54.002725. URL http://ao.osa.org/abstract.cfm?URI=ao-54-10-2725

[35] H. van de Hulst, Light Scattering by Small Particles, Dover Books on 
Physics Series, Dover Publications, 1957.$$
\text { URL http://books .google.fr/books?id=PlHfPMVAFRcC }
$$

[36] C. Oppenheimer, P. Francis, J. Stix, Depletion rates of sulfur dioxide in tropospheric volcanic plumes, Geophysical Research Letters 25 (14) (1998) 2671-2674. doi:10.1029/98GL01988.

[37] I. M. Watson, C. Oppenheimer, Particle size distributions of Mount Etna's aerosol plume constrained by Sun photometry Journal of Geophysical Research: Atmospheres 105 (D8) (2000) 9823-9829. doi:10.1029/ 2000JD900042.

URL http://dx.doi.org/10.1029/2000JD900042

[38] I. M. Watson, C. Oppenheimer, Photometric observations of Mt. Etna's different aerosol plumes, Atmospheric Environment 35 (2001) 3561-3572. doi:10.1016/S1352-2310(01)00075-9.

[39] T. A. Mather, V. I. Tsanev, D. M. Pyle, A. J. S. McGonigle, C. Oppenheimer, A. G. Allen, Characterization and evolution of tropospheric plumes from Lascar and Villarrica volcanoes, Chile, Journal of Geophysical Research: Atmospheres 109 (D21303) (2004). doi:10.1029/2004JD004934.

[40] A. Stohl, C. Forster, A. Frank, P. Seibert, G. Wotawa, Technical note: The Lagrangian particle dispersion model FLEXPART version 6.2, Atmo-

1 spheric Chemistry and Physics 5 (9) (2005) 2461-2474. doi:10.5194/ acp-5-2461-2005.

[41] A. Tiesi, M. Villani, M. DIsidoro, A. Prata, A. Maurizi, F. Tampieri, a Estimation of dispersion coefficient in the troposphere from satellite images of volcanic plumes: Application to mt. etna, italy,

1. Atmospheric Environment 40 (4) (2006) 628 - 638. doi:http: //dx.doi.org/10.1016/j.atmosenv.2005.09.079.

770 URL http://ww.sciencedirect.com/science/article/pii/ $\$ 1352231005009660$ 
[42] T. Di Iorio, A. di Sarra, W. Junkermann, M. Cacciani, G. Fiocco, D. Fu,

n Tropospheric aerosols in the Mediterranean: 1. Microphysical and optical properties, Journal of Geophysical Research: Atmospheres 108 (D10) (2003), 4316. doi:10.1029/2002JD002815.

URL http://dx.doi.org/10.1029/2002JD002815

[43] J. Gómez-Amo, V. Pinti, T. D. Iorio, A. di Sarra, D. Meloni, S. Becagli, V. Bellantone, M. Cacciani, D. Fuà, M. Perrone, The

- June 2007 Saharan dust event in the central Mediterranean: Observations and radiative effects in marine, urban, and sub-urban environments, Atmospheric Environment 45 (30) (2011) 5385 - 5393. doi:http://dx.doi.org/10.1016/j.atmosenv.2011.06.045. URL http://www.sciencedirect.com/science/article/pii/ S1352231011006571

[44] M. Marconi, D. M. Sferlazzo, S. Becagli, C. Bommarito, G. Calzolai, M. Chiari, A. di Sarra, C. Ghedini, J. L. Gómez-Amo, F. Lucarelli, D. Meloni, F. Monteleone, S. Nava, G. Pace, S. Piacentino, F. Rugi, M. Severi, R. Traversi, R. Udisti, Saharan dust aerosol over the central Mediterranean

n Sea: $\mathrm{PM}_{10}$ chemical composition and concentration versus optical columnar measurements, Atmospheric Chemistry and Physics 14 (4) (2014) 20392054. doi:10.5194/acp-14-2039-2014.

URL http://www . atmos-chem-phys . net/14/2039/2014/

[45] P. Kishcha, S. Nickovic, B. Starobinets, A. di Sarra, R. Udisti, S. Becagli, D. Sferlazzo, C. Bommarito, P. Alpert, Sea-salt aerosol forecasts compared with daily measurements at the island of Lampedusa (Central Mediterranean), Atmospheric Research 100 (1) (2011) 28 - 35. doi:http://dx.doi.org/10.1016/j.atmosres.2010.12.021.

a URL http://www.sciencedirect.com/science/article/pii/ S0169809510003686 


\section{Highlights:}

1) Etna's decadal impact in the central Mediterranean is estimated for the first time

2) Transport of Etnean airmasses perturb $\mathrm{SO} 2$ content and aerosols mean size at Lampedusa

3) $40 \%$ (SO2) and 20\% (alpha) exceedances at Lampedusa are attributed to Etna's forcing 